\title{
Principais Problemas Patológicos Investigados em Equipamentos Urbanos de Parque Público
}

\author{
Main Pathological Problems Investigated in Urban Public Park Equipment
}

\author{
Cesar Fabiano Fioriti 1 (Dorcid.org/0000-0001-5461-4495 \\ Bruna Anacleto dos Santos ${ }^{1}$ (D) orcid.org/0000-0003-0670-0860 \\ ${ }^{1}$ Departamento de Planejamento Urbanismo e Ambiente, Faculdade de Ciências e Tecnologia, Universidade Estadual Paulista, \\ Presidente Prudente, Brasil. \\ E-mail do autor principal: Cesar Fabiano Fioriti fioriti@fct.unesp.br
}

\section{Resumo}

Apesar do avanço tecnológico no campo das técnicas e dos materiais de construção, tem-se observado um grande número de edificações e equipamentos públicos relativamente jovens apresentando problemas patológicos de toda sorte. Dessa maneira este trabalho trata de estudo de caso realizado nos equipamentos urbanos públicos pertencentes ao Parque do Povo, localizado no município de Presidente Prudente, em que por meio de vistorias foram identificadas as manifestações patológicas existentes na pista de skate, no teatro de arena, na fonte com espelho d'água, na pista de caminhada, em quiosques, em pergolados, em bancos e na quadra poliesportiva. A metodologia empregada envolveu a seguinte sequência: (1) levantamento visual das manifestações patológicas (utilizando como auxílio seu registro fotográfico), (2) apresentação dos aspectos gerais, (3) apresentação das causas prováveis, (4) apresentação do diagnóstico mais provável e (5) possibilidade de solução de reparo das anomalias identificadas. Os resultados apontaram manifestações patológicas em revestimento de argamassa (fissuras e eflorescências), alvenaria (rachaduras e cedimento), concreto (estufamento e cedimento), revestimento cerâmico (eflorescências e descolamentos) e aço (corrosão). Por fim, os problemas relatados são decorrentes, em sua maioria, a falhas de execução e/ou projetual, tal como a falta de manutenção preventiva dos locais vistoriados.

Palavras-Chave: Equipamentos urbanos; Degradação; Anomalias.

\begin{abstract}
Despite the technological advances in the field of building materials and techniques, a large number of buildings and public facilities have been observed, relatively young, presenting pathological problems of all kinds. In this way, this paper deals with a case study carried out in the public urban equipments belonging to the Park of the People, located in the municipality of Presidente Prudente, in which the pathological manifestations existing in the skating rink, the arena theater, the water fountain, hiking trail, kiosks, pergolas, benches and on the sports court. The methodology employed involved the following sequence: (1) visual survey of pathological manifestations (using as an aid their photographic record), (2) presentation of general aspects, (3) presentation of probable causes,
\end{abstract}




\section{Principais Problemas Patológicos Investigados em Equipamentos Urbanos de Parque Público}

(4) presentation of the most likely diagnosis and (5) possibility of repairing the identified anomalies. The results indicated pathological manifestations of mortar (fissures and efflorescence), masonry (cracks and repression), concrete (caving and repression), ceramic coating (efflorescence and detachment) and steel (corrosion). Finally, the problems reported are due, for the most part, to execution and / or design flaws, as well as the lack of preventive maintenance of the surveyed sites.

Key-words: Urban equipments; Degradation; Anomalies.

\section{Introdução}

O termo patologia é originário do grego páthos, que significa doença, e lógos, correspondendo a estudo. De acordo com a etimologia, patologia significa o estudo das doenças e, originalmente, foi aplicado à medicina, a fim de relatar as modificações anatômicas e funcionais causadas pelas doenças no organismo (FREIRE [1]).

Segundo Helene [2], "patologia é a parte da engenharia que estuda os sintomas, os mecanismos, as causas e as origens dos defeitos das construções civis, ou seja, é o estudo das partes que compõem o diagnóstico do problema".

Conforme Iantas [3], as manifestações patológicas são modificações estruturais e ou funcionais causadas por doença no organismo, ou seja, tudo que promove a degradação do material ou de suas propriedades físicas e ou estruturais o qual esteja sendo solicitado. As edificações também podem apresentar anomalias, comparáveis as doenças: trincas, rachaduras, fissuras, manchas, descolamentos, deformações, rupturas, corrosões, oxidações, entre outros. Também pode ser entendida como o baixo ou o fim do desempenho da estrutura, em relação à estabilidade, estética, funcionalidade e, principalmente, durabilidade da mesma com relação às condições que está submetida.

Para Lima [4], a sintomatologia é um importante assunto a ser abordado nas manifestações patológicas, pois se trata do quadro que torna evidente que a construção é acometida por algum processo patológico.

Segundo Thomaz [5], muitos problemas patológicos ocorrem devido ao envelhecimento natural da edificação, no entanto, podem ter origem em erros de projeto, erros na construção, ou até mesmo à falta de manutenção. O citado autor ainda destaca à desconsideração de agentes agressivos ou mesmo ao pequeno conhecimento de processos degenerativos.
Inúmeras são as anomalias que afetam os edifícios. Entre elas, ainda segundo Thomaz (2001), destaca-se a evolução tecnológica da construção civil no Brasil, que induziu a realização das obras em um tempo menor, utilizando estruturas e materiais cada vez mais leves. Tais fatos, juntamente com o despreparo dos profissionais, tanto de projeto quanto de produção, vêm provocando a queda gradativa da qualidade das construções no país. $O$ autor complementa ainda que a incompatibilidade dos projetos, bem como o seu pouco detalhamento, juntamente com a falta de planejamento e de fiscalização das obras, colabora para o agravamento do quadro atual.

Manifestações patológicas também se originam devido os profissionais com formação em outro país não conhecerem as características climáticas, de insolação e regime dos ventos do Brasil, onde encontramos uma variedade climática muito diversificada. Até bons profissionais erram quando não levam em consideração as mudanças climáticas ocorridas nas últimas décadas. Além disso, os materiais e os processos construtivos também diferem muito, nosso cimento é muito diferente do europeu, nossas casas são construídas com tijolos ou blocos e nos Estados Unidos as casas e sobrados são em sua maioria de madeira, e assim por diante. Desta maneira, não basta o edifício ser bonito e funcional, deve ser bom para a vida saudável no interior dele, isto é, é necessário ver a habitabilidade da edificação.

Diante disto, este trabalho trata de estudo de caso realizado nos equipamentos urbanos públicos pertencentes ao Parque do Povo, localizado no município de Presidente Prudente, em que por meio de vistorias foram identificadas manifestações patológicas existentes na pista de skate, no teatro de arena, na fonte com espelho d'água, na pista de caminhada, em quiosques, em pergolados, em bancos e na quadra poliesportiva. 


\section{Metodologia}

O estudo de caso foi a alternativa expositiva escolhida neste trabalho para apresentar o equacionamento das soluções dos conflitos que o envolvem. Sendo assim, serão relatados os procedimentos metodológicos utilizados para o desenvolvimento do trabalho de campo e seus desdobramentos. A metodologia foi constituída basicamente de seis etapas, onde esquematicamente são apresentadas na Figura 1.

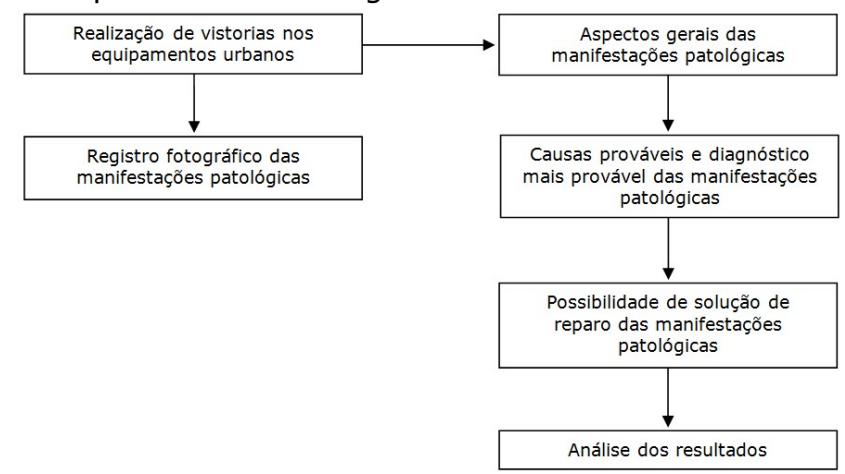

Figura 1: Esquema das etapas desenvolvidas no trabalho. Fonte: Autores (2016).

Por meio das seis etapas apresentadas, verifica-se que foram realizados levantamentos que deram suporte técnico para o desenvolvimento dessas atividades. Assim, o estudo dos problemas patológicos a partir de suas manifestações permite um conhecimento mais aprofundado das causas, subsidia os trabalhos de recuperação e manutenção e contribui para um maior entendimento de cada uma das etapas dos processos de produção dos equipamentos urbanos, possibilitando a adoção de medidas preventivas.

Algumas limitações foram encontradas no desenvolvimento desse trabalho, merecendo destaque as informações incompletas referentes as etapas de execução das edificações e a impossibilidade de obtenção de amostras por meio de processo destrutivo.

Desta forma, salienta-se que não fez parte deste trabalho entrar no mérito da qualificação e da atuação dos profissionais e empresas que participaram dos projetos e execução destas obras, sendo o foco único o levantamento das manifestações patológicas vistas sob a ótica da sintomatologia.

\section{Resultados}

\subsection{Breve histórico do Parque do Povo}

O Parque do Povo, destacado na Figura 2 pela cor verde, trata-se de uma área de lazer com mais de 6 $\mathrm{km}$ de extensão que percorre uma área nobre da cidade, desde a Avenida Manoel Goulart, próximo ao Prudenshopping, até a Avenida Brasil.

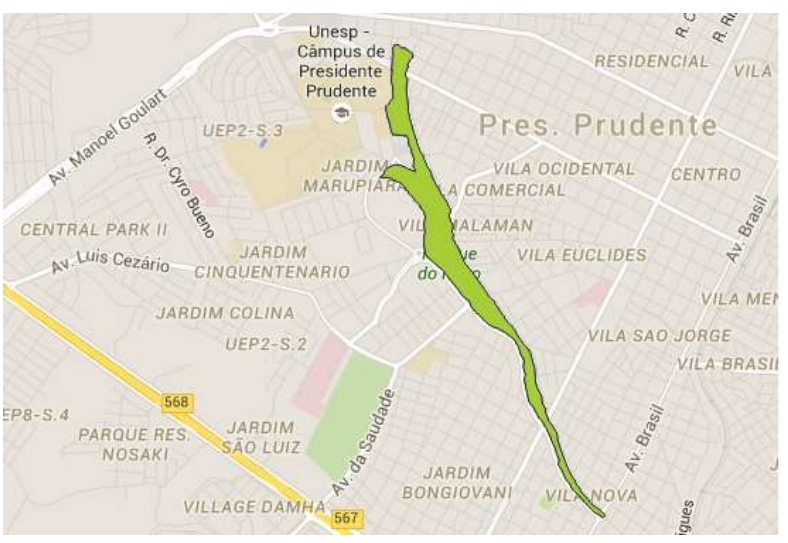

Figura 2: Localização do Parque do Povo. Fonte: Google Maps (2016) - editado.

Anteriormente a construção do Parque do Povo, o Córrego do Veado onde o parque está localizado, era uma região de difícil acesso e extremamente desvalorizada. Devido a expansão urbana aumentouse a necessidade de acesso e circulação na região. Foi então que surgiu o programa denominado "Fundo de Vale" em 1976, por iniciativa da Prefeitura Municipal, que tinha como objetivo canalizar um trecho do Córrego do Veado e por meio de um processo de urbanização valorizar o local. No entanto, quando o parque foi inaugurado em 1982, não foi executado o projeto inicial completo, apenas parte dele. Mas já foi o suficiente para provocar grandes mudanças no local e valorizar a região (FRAZILI et al. [6]).

Atualmente, o parque consiste em uma extensa área de lazer verde localizada num fundo de vale. Possuí equipamentos urbanos de lazer, como pista de skate, quadra poliesportiva, ciclovias, pistas de caminhada, campo de futebol, quiosques, playground, academia de idosos, entre outros, como mostra a Figura 3. 


\section{Principais Problemas Patológicos Investigados em Equipamentos Urbanos de Parque Público}
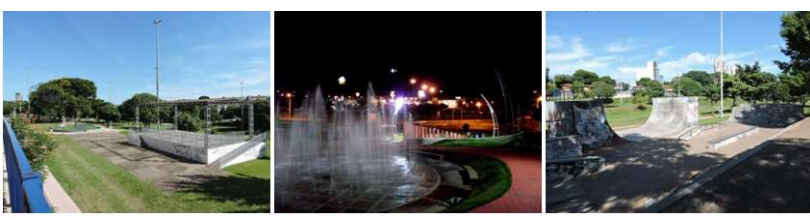

Figura 3: Parque do Povo, com detalhe do palco para shows, fonte com o teatro de arena ao fundo, além da pista de skate.

Fonte: Autores (2016).

O parque é utilizado pelos cidadãos tanto durante a semana quanto aos finais de semana e feriados, para diversas atividades. Esse uso constante traz mais segurança ao local e comprova a qualidade do espaço urbano em questão. Essa qualidade influencia não somente no parque, mas também nas áreas próximas, tanto é que houve uma forte valorização de toda área localizada no entdo parque $e$, principalmente, em seu perímetro - houve instalação de vários estabelecimentos comerciais, como academias, bares, restaurantes, lojas, edifícios de múltiplos pavimentos, etc.

Recentemente o parque passou por algumas pequenas reformas, alguns mobiliários como bancos, academia de idosos e algumas edificações como os banheiros foram substituídos ou mesmo reformados.

\subsection{Manifestações patológicas identificadas nos equipamentos urbanos}

Os Quadros 1 a 7 apresentam algumas das manifestações patológicas identificadas, em que se pode relacionar o levantamento dos aspectos gerais, as causas prováveis, o diagnóstico provável e a possibilidade de solução de reparo, a partir dos dados de campo e do registro fotográfico realizado.

Quadro 1: Eflorescência no revestimento argamassado, localizada na fonte com espelho d'água.

\begin{tabular}{l}
\hline \\
Aspectos gerais \\
Manchas esbranquiçadas na parte superior do revestimento; \\
Alteração da textura do revestimento; \\
Pequenos pontos de descolamento da pintura próximos a região \\
das manchas esbranquiçadas. \\
\hline Causas prováveis \\
Excesso de umidade; \\
Acumulo de água e infiltrações; \\
Alta permeabilidade do revestimento;
\end{tabular}

Fissuras na superfície do revestimento favorecendo a entrada da
água;
Percolação d'água;
Migração e posterior evaporação de soluções aquosas salinizadas.
Diagnóstico mais provável
Eflorescências causadas pela percolação de água no revestimento
argamassado, infiltrando em grande parte pelo rejunte das placas
assentadas na parte superior da alvenaria. A ocorrência de
variações térmicas faz com que a água infiltrada carregue consigo
sais dos materiais que ficam depositados na superfície, quando a
água evapora esses depósitos salinos dão origem as manchas
esbranquiçadas na superfície do revestimento.
Possibilidade de solução de reparo
1. Aplicar rejunte acrílico entre as placas assentadas na parte
superior da alvenaria;
2. Limpar a superfície;
3. Aplicar um preparador de parede a base de água;
4. Aplicar um selante acrílico e a tinta.

Fonte: Autores (2016).

Quadro 2: Rachaduras horizontais ao longo da arquibancada do teatro de arena.

\begin{tabular}{l} 
Aspectos gerais \\
Aberturas variando entre 15 até 83 mm na alvenaria que constitui \\
a arquibancada \\
Aberturas predominantemente na horizontal ao longo de toda a \\
estrutura; \\
Desagregação da argamassa de revestimento em alguns pontos \\
das rachaduras; \\
Alvenaria aparente nos pontos com desagregação da argamassa de \\
revestimento. \\
Causas prováveis \\
Movimentação do solo (recalque); \\
Má qualidade da mão de obra; \\
Incompatibilidade entre os materiais utilizados; \\
Solicitações de fortes tensões expansivas. \\
Diagnóstico mais provável \\
Movimentação do solo, ou seja, recalque ao longo de toda a altura \\
dos degraus da arquibancada. O recalque pode ter sido proveniente \\
de um aterro mal compactado, que posteriormente veio a ocasionar \\
as rachaduras horizontais ao longo da arquibancada. \\
Possibilidade de solução de reparo \\
rachadura; \\
aberturadara do rachado recalque já estabilizado, deve-se limpar a \\
3. Reaplicar a argamassa, reaplicar o selante acrílico e a tinta. \\
\hline
\end{tabular}
Fonte: Autores (2016).

Quadro 3: Estufamento do piso de concreto da pista de caminhada. 


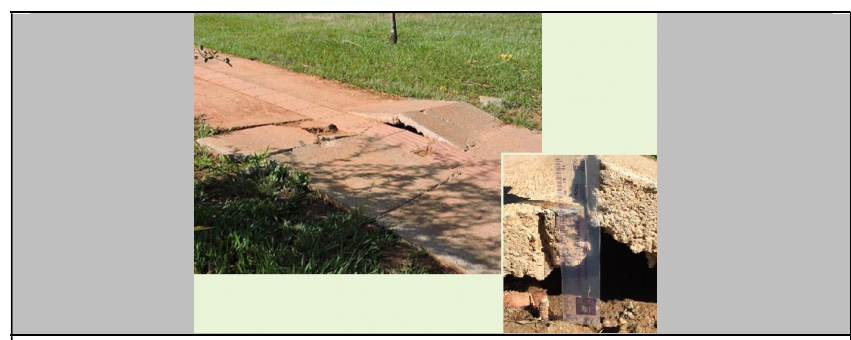

Aspectos gerais

Estufamento de aproximadamente $100 \mathrm{~mm}$ do concreto da pista;

Rachaduras e rompimentos generalizados na região afetada;

Comprometimento da segurança, acessibilidade e conforto dos usuários;

Rachaduras e descolamento das placas táctil-visuais da pista.

\section{Causas prováveis}

Movimentação do substrato;

Má qualidade da mão de obra

Movimentação térmica;

Ausência de malha de aço;

Juntas de dilatação insuficientes

\section{Diagnóstico mais provável}

Juntas de dilatação insuficientes associada a ausência da malha de aço, pois quando ocorre a dilatação devido a variação térmica no concreto, o material não encontra espaço suficiente para expandir, rompendo-se. A ausência da malha de aço também contribui para o rompimento do concreto, pois ela ajudaria a manter a integridade do calçamento.

\section{Possibilidade de solução de reparo}

1. Retirar o concreto danificado;

2. Reaplicar o lastro de brita e reconcretar a região;

3. Executar juntas de dilatação não somente na região afetada, mas ao longo de toda a pista da caminhada.

Fonte: Autores (2016).

Quadro 4: Rachaduras diagonais em alvenaria da pista de skate.

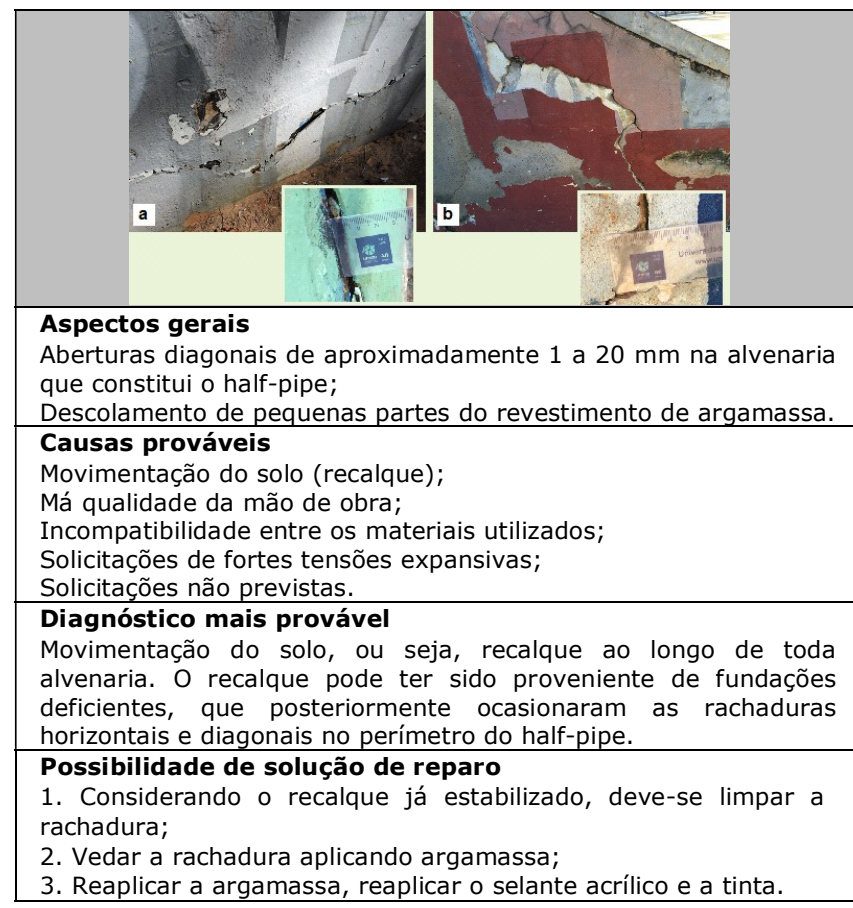

Fonte: Autores (2016).

Quadro 5: Cedimento do pavimento intertravado do passeio.

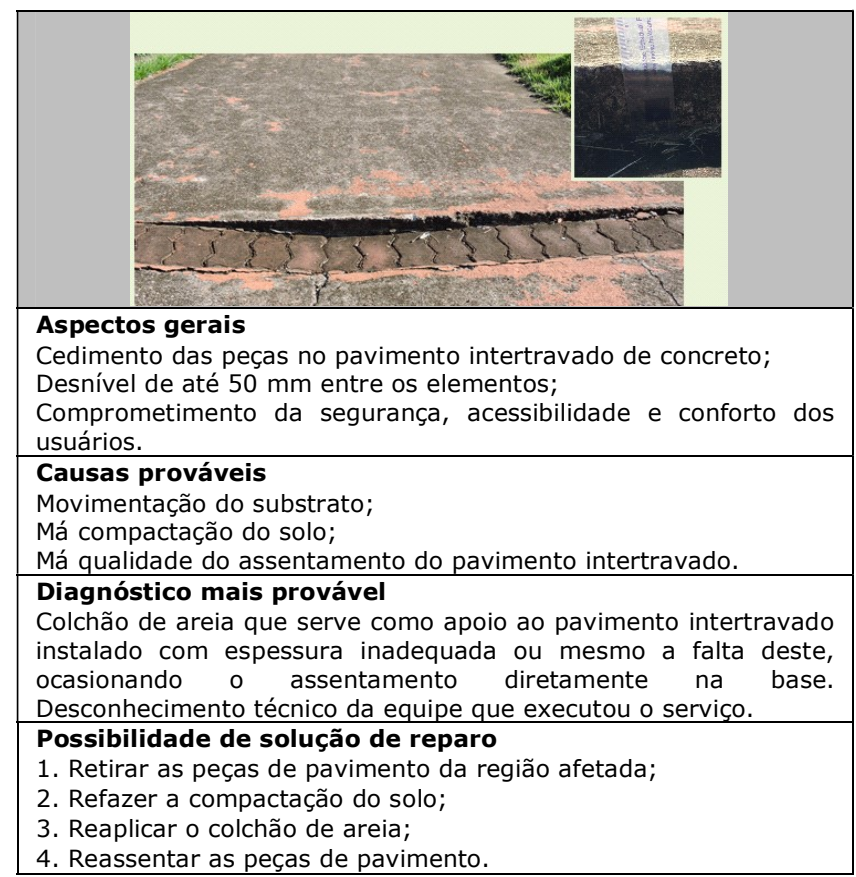
Fonte: Autores (2016).

Quadro 6: Descolamento do revestimento em granito dos bancos.

\begin{tabular}{l}
\hline Aspectos gerais \\
Revestimento em granito descolado; \\
Argamassa de assentamento aparente (Fig. b). \\
\hline Causas prováveis \\
Argamassa de assentamento inadequada; \\
Má qualidade da mão de obra. \\
\hline Diagnóstico mais provável \\
Argamassa de assentamento inadequada ou de baixa qualidade. \\
Neste caso, utilizou-se um revestimento de elevada densidade, o \\
granito, que demanda uma argamassa adequada para garantir \\
aderência entre o material de revestimento e a alvenaria, como a \\
argamassa do tipo AC III ou ainda colas do tipo epóxi. \\
\hline Possibilidade de solução de reparo \\
1. Realizar a limpeza da região afetada, removendo todos os \\
fragmentos de argamassa de assentamento; \\
2. Reaplicar a argamassa de assentamento e/ou do tipo epóxi, \\
reassentar as peças de granito e finalizar com o rejunte.
\end{tabular}
Fonte: Autores (2016).

Quadro 7: Corrosão nas bases de pilares dos pergolados

http: //dx.doi.org/10.25286/repa.v2i3.679 


\section{Principais Problemas Patológicos Investigados em Equipamentos Urbanos de Parque Público}

\begin{tabular}{l} 
Aspectos gerais \\
Corrosão nos cordões de solda entre as chapas de topo e pilares; \\
Perda de parte do acabamento (pintura); \\
Manchas marrom-avermelhadas devido ao processo existente de \\
corrosão nas chapas de topo; \\
Redução da massa das chapas de topo; \\
Redução da massa dos perfis "U" (Fig. b); \\
Mancha marrom-avermelhada devido ao processo de corrosão na \\
ligação entre os perfis "U" (Fig. b). \\
Causas prováveis \\
Falta de manutenção preventiva; \\
Excesso de umidade; \\
Ação química da água de chuva que fica acumulada nas chapas de \\
topo; \\
Elementos em contato com águas residuais. \\
\hline Diagnóstico mais provável \\
Ação química da água de chuva que penetra nos perfis "U" dos \\
pilares pela parte superior e escorre por todo o comprimento do \\
pilar. \\
\hline Possibilidade de solução de reparo \\
1. Limpeza superficial com jato de granalha de aço; \\
2. Realizar a vedação com solda dos perfis, tanto da parte superior \\
quanto da parte inferior, conforme a necessidade; \\
3. Renovar da camada de proteção, de modo a criar uma barreira \\
efetiva entre o metal e o ambiente agressivo e reforço da \\
estrutura; \\
4. Reaplicar a tinta. \\
\hline
\end{tabular}
Fonte: Autores (2016).

Cabe mencionar que além dos problemas patológicos apresentados, o Parque do Povo também é acometido por anomalias referentes a: fissuras em revestimentos argamassados na fonte com espelho d'água, descolamento da pintura em revestimento argamassado da fonte com espelho d'água, proliferação de manchas escuras em revestimento argamassado da pista de skate, eflorescência em revestimento cerâmico de quiosque, descolamento entre alvenarias de sanitário, desagregação da argamassa de revestimento de sanitário, descolamento do revestimento cerâmico em quiosque, corrosão em pilares de pergolados e da quadra poliesportiva, corrosão em vigas de pergolados e corrosão em base de pilares na quadra poliesportiva.

\subsection{Análise geral}

O Quadro 8 apresenta uma síntese dos diagnósticos desenvolvidos, sendo que tal tabela contempla todos os materiais analisados durante as vistorias, bem como todas as manifestações patológicas identificadas, indicando por meio de lacunas hachuradas as anomalias presentes em cada um dos diferentes materiais.
Quadro 8: Anomalias identificadas em diferentes materiais.

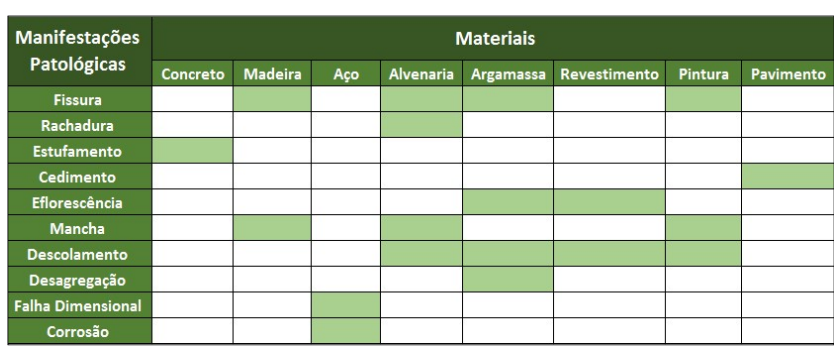

Fonte: Autores (2016).

Observando o Quadro 8, pode ser notado que as manifestações patológicas mais comuns entre os diferentes materiais, no local de análise, são: fissuras, descolamentos e manchas.

Apesar de a corrosão ser uma manifestação patológica quase que exclusiva dos metais, aço no caso, esta foi identificada muitas vezes nas vistorias, por estar presente em praticamente todas as análises realizadas em elementos do material em questão.

Sobre as manifestações patológicas identificadas em elementos de alvenaria, a mais comum é a fissuração.

As fissuras nas alvenarias são divididas de acordo com sua forma de manifestação, ou seja, seu desenho, que pode ser geométrico ou mapeado. As geométricas, também chamadas de isoladas, podem ocorrer tanto nos elementos da alvenaria - blocos e tijolos - quanto em suas juntas de assentamento. As mapeadas, também chamadas de disseminadas, podem ser formadas por retração das argamassas, por excesso de finos no traço ou por excesso de desempenamento. No geral, elas têm forma de "mapa" e, com frequência, são aberturas superficiais (CORSINI [7]).

Ambos os tipos de fissuras, citados anteriormente, foram detectados na mesma proporção durante as vistorias, nos elementos de alvenaria. Fissuras de mapeamento foram identificadas juntamente as manchas escuras e ao descolamento da pintura. Já as fissuras geométricas são encontradas associadas à rachaduras. Aliás, na grande maioria dos casos de fissuras, estas se encontram associadas a outras anomalias, principalmente à rachaduras.

O diagnóstico de duas, das três rachaduras identificadas, está associado à movimentação de solo, recalques ou ainda a solicitações não previstas. Já o terceiro está associado à amarração inadequada entre dois elementos (pilar de concreto e parede de alvenaria). 
Em uma comparação entre as manifestações patológicas identificadas em alvenaria e em aço, observa-se que os problemas identificados em alvenarias são provenientes, em sua maioria, de falhas projetuais ou executivas. Apenas as manchas em alvenaria ( $10 \%$ ) estão relacionadas diretamente à umidade. Diferente das manifestações patológicas em aço, pois mais de $83 \%$ destas estão relacionadas à umidade.

As manifestações patológicas identificadas nos elementos de argamassa são bem mais distribuídas. Foram identificadas quatros diferentes anomalias, todas elas relacionadas à presença de umidade, superando os índices de manifestações patológicas ocasionados pela umidade tanto em elementos de aço quanto em alvenaria.

Metade dos diagnósticos estão relacionados à propriedades do material em questão e a outra metade relacionada à falhas de execução e falta de manutenção.

É importante salientar que, manifestações patológicas como as fissuras contribuem de maneira efetiva para que surjam novas anomalias, como eflorescências, descolamento e desagregação. Pois, todas as anomalias citadas são provenientes da presença da umidade, e as fissuras tornam os elementos mais expostos a ação de agentes externos, como poeira, poluição, água entre outros. Deste modo, as fissuras acabam por contribuir para que a umidade se instale e consequentemente ocasione as outras anomalias citadas logo acima.

Os problemas patológicos mais comumente encontrados em pinturas são, assim como nos elementos em alvenaria, as fissuras. Esta anomalia está presente em $50 \%$ dos casos. Além da própria anomalia, as fissuras tornam as superfícies dos materiais mais expostas e contribuem para que surjam outros problemas patológicos, relacionados á ação dos agentes externos, principalmente á umidade. Exemplo desses outros problemas patológicos são os descolamentos e manchas, anomalias que também foram identificadas em pinturas.

Todas as manifestações patológicas identificadas em pinturas podem ser agravadas pela umidade, situação semelhante a que ocorre nos elementos de argamassa. Além disso, para ocorrência de manchas, acarretadas pela presença de microrganismo como no caso identificado, é essencial que haja umidade.

Em suma, mais de metade $(55,55 \%)$ de todas as manifestações patológicas identificadas estão relacionadas a umidade, seja pela presença de água na superfície dos elementos ou infiltração desta.

A Figura 4 informa uma contabilização das origens das manifestações patológicas identificadas, possibilitando uma comparação mais objetiva e didática das principais origens das anomalias identificadas em toda extensão do Parque do Povo.

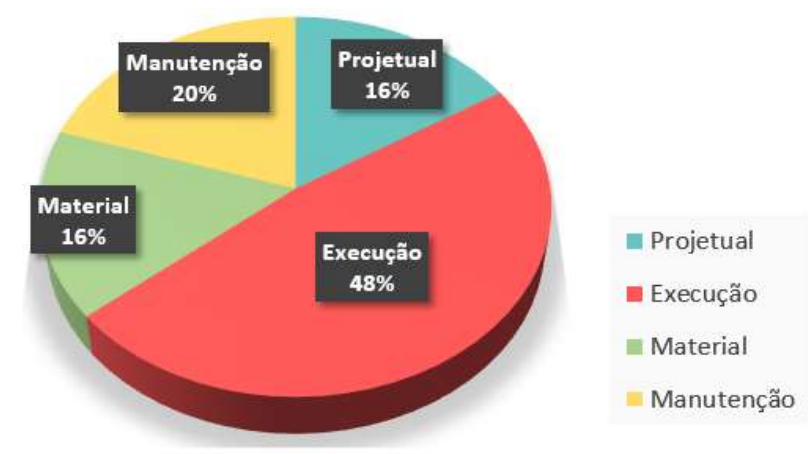

Figura 4: Síntese das origens das manifestações patológicas identificadas.

Fonte: Autores (2016).

A Figura 4 aponta que quase metade (48\%) das manifestações patológicas identificadas são originadas em falhas durante o processo de execução. Resultado que se aproxima muito com o que afirma Carmona e Marega (1988) apud Verçoza [8], que a maioria das manifestações patológicas tem sua origem na fase de execução, apesar deste apresentar um número com uma diferença pequena.

Outra observação muito relevante é que, apesar do parque ter passado por um recente processo de reforma/revitalização, muitas edificações, estruturas e equipamentos públicos se encontram em necessidade de manutenção, pois nestes se identificam manifestações patológicas. Lima [4] denomina esse quadro apresentado por sintomatologia. Esta situação é muito comum, apesar de Helene [2] afirmar que os custos de manutenção crescem em progressão geométrica, e que custos para manutenção corretiva são cerca de cinco vezes maiores se comparados a custo de manutenção preventiva, segundo a Lei de Evolução dos Custos. Sem contar é claro, o risco de se perder o elemento ou a edificação, pois quando as manifestações patológicas se encontram em nível muito avançado

http: / / dx.doi.org/10.25286/repa.v2i3.679 
pode ser que não haja mais reparos possíveis que sejam capazes de recuperar a edificação ou até mesmo, que os reparos sejam possíveis, porém inviáveis economicamente.

As manifestações patológicas identificadas, em geral, se caracterizam como falhas de média monta, não chegando a comprometer a estrutura dos elementos, porém comprometem a estética dos equipamentos. Muitas vezes também comprometem a segurança e o conforto dos usuários; como no caso das situações apresentadas nos Quadros 3 e 5, pois o estado em que o piso intertravado se encontra poderia facilmente causar um acidente aos caminhantes que por ali passarem, principalmente no caso da pista de caminhada, onde a situação se encontra em um estado bem crítico.

\section{Conclusões}

Por meio deste trabalho e das análises realizadas, é possível afirmar que muitas das manifestações patológicas identificadas poderiam ter sido minimizadas, e até mesmo evitadas, caso houvesse maior controle das etapas do processo construtivo, e que ao serem associadas a uma efetiva manutenção dos equipamentos urbanos, poderiam proporcionar maior qualidade e vida útil aos elementos.

Desta forma, foi possível constatar que o principal fator da existência de tantos problemas detectados deve-se, predominantemente, à falta de manutenções adequadas aos equipamentos urbanos, que não são realizadas de forma constante e preventiva, contribuindo para o aparecimento das manifestações patológicas, como também para o aumento do grau e intensidade delas, acarretando na necessidade de processos de reparos e reestruturação, afetando o funcionamento do elemento e levando a um gasto financeiro maior do que se houvesse uma prevenção efetiva e constante.

Por fim, anseia-se que esse trabalho possa expor a projetistas, construtores e usuários, os problemas patológicos que podem ocorrer em equipamentos urbanos públicos quando estes não recebem os cuidados e procedimentos necessários para seu funcionamento ideal, e com isso, proporcionar maior atenção e consciência por parte desses, a fim de que se atentem para as precauções e especificações de procedimentos a serem tomadas para a construção, como também para a utilização de um equipamento urbano.

\section{Agradecimento}

A FAPESP - Fundação de Amparo a Pesquisa do Estado de São Paulo, pela concessão da bolsa de iniciação científica a aluna.

\section{Referências}

[1] FREIRE, A. Patologia nas edificações públicas do estado do Paraná: estudo de caso da unidade escolar padrão 023 da Superintendência de Desenvolvimento Escolar - SUDE. 2010. Monografia (Especialização em Construção de Obras Públicas) - Universidade Federal do Paraná, Curitiba.

[2] HELENE, P. R. L. Manual para reparo, reforço e proteção de estruturas de concreto. São Paulo: Editora Pini, 1992.

[3] IANTAS, L. C. Estudo de caso: análise de patologias estruturais em edificação de gestão pública. 2010. Monografia (Especialização em Construção de Obras Públicas) - Universidade Federal do Paraná, Curitiba.

[4] LIMA, P. R. B. Consideração do projeto no desempenho dos sistemas construtivos e qualidade da edificação - Proposição de um modelo de banco de dados. 2005. Dissertação (Mestrado) - Universidade Federal de Minas Gerais, Belo Horizonte.

[5] THOMAZ, E. Tecnologia, gerenciamento e qualidade na construção. São Paulo: Coedição IPT/EPUSP/Editora Pini, 2001.

[6] FRAZILI, L. G. R.; ALVES, S. L.; ALBANO, M. P.; YEDA, R. M. Análise do parque do povo como agente da reurbanização do fundo de vale, e desenvolvimento da cidade de Presidente Prudente-SP. Colloquium Humanarum, v. 10, n. Especial, jul-dez, 2013.

[7] CORSINI, R. Trinca ou fissura? Revista Téchne no 160, julho de 2010. Disponível em: <http://techne.pini.com.br/engenhariacivil/160/trinca-ou-fissura-como-se-originamquais-os-tipos-285488-1.aspx>. Acesso em: 13 jul. 2016.

[8] VERÇOZA, E. J. Patologias das edificações. Porto Alegre: Editora Sagra, 1991. 